\title{
A DESCENTRALIZAÇÃO DA INDÚSTRIA ${ }^{1}$
}

\section{Piotr Kropotkin}

Quem não recorda do notável capítulo com que Adam Smith abre sua investigação a respeito da natureza e as causas da riqueza das nações? Mesmo aqueles economistas contemporâneos que raramente retomam as obras do pai da Economia Política, e com frequência esquecem as ideias que as inspiraram, sabem este capítulo praticamente de cor, de tanto que ele tem sido reproduzido e recopiado. Ele se tornou um artigo de fé e a história econômica do século passado ${ }^{2}$, desde que Adam Smith o escreveu, tem sido, digamos assim, seu comentário.

"Divisão do trabalho" foi sua bandeira e a divisão e subdivisão - a permanente subdivisão - de funções foi levada tão longe, até conseguir dividir a humanidade em castas, que estão quase tão fortemente constituídas como aquelas da antiga Índia. Temos, primeiro, a ampla divisão entre produtores e consumidores: de um lado, produtores que consomem pouco, de outra, consumidores que produzem pouco. Depois, entre os primeiros, uma série de novas subdivisões: o trabalhador manual e o intelectual, profundamente separados entre si, em prejuízo de ambos; os trabalhadores agrícolas e os da fábrica e, entre os últimos, inúmeras subdivisões outra vez, tão pequenas, que o ideal moderno de trabalhador parece ser um homem ou uma mulher, e até uma jovem ou um rapaz, sem conhecimento de nenhuma atividade artesanal, sem a menor ideia sobre a indústria em que se emprega, capaz unicamente de fazer, ao longo do dia e pela vida inteira, nada mais do que a mesma parte infinitesimal de uma coisa: empurrando um vagão

Primeiro capítulo do livro de Piotr Alexeyevich Kropotkin, "Fields, Factories and Workshops" ("Campos, Indústrias e Oficinas"), 2010 (1898), disponível em: https:// theanarchistlibrary.org/library/petr-kropotkin-fields-factories-and-workshops-or-industry-combined-with-agriculture-and-brain-w (acessado em março de 2013). A tradução aqui apresentada foi cotejada com a versão em espanhol: "Campos, Fabricas y Talleres" disponível em: http://www.bsolot.info/wp-content/uploads/2011/02/Kropotkin_Piotr-Campos_fabricas_y_talleres.pdf. Tradução: Rodolpho Jordano Netto, Rogério Haesbaert e Daniel Sanfelici. ${ }^{2}$ Século XIX (N.T.) de carvão em uma mina, desde os treze até aos sessenta anos, ou fazendo a mola de um canivete, ou ainda "a décima oitava parte de um alfinete". Meros servos de uma determinada máquina, meras partes de carne e osso de alguma imensa maquinaria, não têm ideia de como e por que a máquina executa seus movimentos rítmicos.

0 artesão habilidoso se vê desprezado, como sobrevivente de um passado condenado a desaparecer. 0 artista, que antigamente encontrava prazer estético pelo trabalho de suas mãos, foi substituído pelo escravo humano de um escravo de ferro. Mas não para por aí: até o trabalhador agrícola, antes acostumado a encontrar um alívio das agruras da vida na casa de seus antepassados - futuro lar de seus filhos - em seu amor à terra e em sua íntima relação com a natureza; até mesmo ele foi condenado a desaparecer, para o bem da divisão do trabalho. Ele é um anacronismo, como dizemos: deve ser substituído, numa grande fazenda [Bonanza farm ${ }^{3}$ ], por um trabalhador temporário contratado durante o verão e descartado quando chega o outono; um desconhecido, que nunca mais voltará a ver o campo que uma vez cultivou em sua vida. "A reforma da agricultura, de acordo com os verdadeiros princípios da divisão do trabalho e da organização industrial moderna é questão de poucos anos", dizem os economistas.

Deslumbrados com os resultados obtidos em nosso século ${ }^{4}$ de maravilhosas invenções, especialmente na Inglaterra, nossos economistas e homens políticos foram ainda mais longe em seus sonhos de divisão do trabalho. Proclamaram a necessidade de dividir a humanidade inteira em fábricas [workshops] nacionais, tendo cada uma delas sua especialidade particular. Pensava-se, por exemplo, que a Hungria e a Rússia estariam predestinadas

3"Bonanza farm" era o nome dado a grandes fazendas em processo de mecanização no Oeste dos Estados Unidos ao final do século XIX, embrião, poderíamos dizer do que hoje se denomina "agronegócio". (N.T.) ${ }^{4}$ Século XIX (N.T.) 
pela natureza a produzir trigo, para alimentar os países industriais; que a Inglaterra deveria abastecer todos os mercados com tecidos de algodão, ferragens e carvão; a Bélgica com tecidos de lã, e assim por diante. Até mesmo dentro de cada nação, cada região deveria ter sua própria especialidade. Assim vinha ocorrendo há algum tempo e assim deveria continuar. Dessa forma vêm se fazendo fortunas que, do mesmo modo, seguirão sendo feitas.

Tendo sido proclamado que a riqueza das nações é medida pela quantidade de lucros obtidos por poucos, e que os maiores lucros são feitos por meio de uma especialização do trabalho, a questão não era concebível senão quando os seres humanos se submetessem sempre a tal especialização, quando as nações pudessem se especializar como se fossem operários. Se a teoria fosse boa para os dias de hoje, porque deveríamos nos preocupar com o amanhã? 0 amanhã poderia trazer sua própria teoria!

E assim tem sido feito: a estreita concepção de vida que consistia em pensar que os lucros são o único grande estímulo para a sociedade humana, e a obstinada ideia que supõe que o que existia ontem vai existir para sempre, provaram-se em desacordo com as tendências da vida humana, a qual tomou outra direção. Ninguém negará o alto grau de produção que se pode alcançar por meio da especialização. Porém, precisamente à medida em que o trabalho que se exige do indivíduo na produção moderna se torna mais simples e mais fácil de aprender e, por conseguinte, também mais monótono e cansativo, mais destacada se torna a necessidade do indivíduo em diversificar seu trabalho, em exercitar todas as suas habilidades. A humanidade percebe que não há nenhuma vantagem para a comunidade condenar um ser humano a estar sempre no mesmo lugar, numa fábrica [workshop] ou numa mina, e que nada se ganha em privá-lo de um trabalho que o colocaria em livre contato com a natureza, fazendo dele parte consciente de uma grande todo, um parceiro dos mais elevados prazeres da ciência e da arte, do trabalho livre e da criação.

Também as nações se negam a ser especializadas: cada uma é um composto agregado de gostos e inclinações, de vontades e recursos, de capacidades e poderes inventivos. O território ocupado por uma nação é igualmente um tecido muito variado de solos e climas, de montes e vales, de encostas, que conduzem a variedades ainda maiores de territórios e de raças. A variedade é o caráter distintivo, tanto do território quanto de seus habitantes, e essa variedade implica também uma variedade de ocupações. A agricultura demanda a existência das manufaturas, e estas sustentam a agricultura. Ambas são inseparáveis, e sua mútua combinação e integração produz os mais amplos resultados. À medida que o conhecimento técnico se torna um domínio virtualmente generalizado, à medida que se torna internacional, e que não é possível mais mantê-lo oculto, cada nação adquire os meios de aplicar toda a variedade de suas energias a toda a variedade de empreendimentos industriais e agrícolas.

0 conhecimento ignora limites políticos artificiais. 0 mesmo se passa com as indústrias, e a presente tendência humana é de ter a maior variedade possível de indústrias reunidas ao lado da agricultura, em cada país e em cada região distinta. As necessidades da aglomeração humana correspondem assim às necessidades do indivíduo e, enquanto uma divisão temporária de funções permanece como a mais segura garantia de êxito em cada empreendimento particular, a divisão permanente está condenada a desaparecer e a ser substituída por uma variedade de ocupações intelectuais, industriais e agrícolas - correspondentes às diferentes aptidões do indivíduo, assim como à variedade de capacidades dentro de cada agregado de seres humanos.

Assim, quando saímos da escolástica de nossos livros e examinamos a vida humana em seu conjunto, logo descobrimos que, enquanto todos os benefícios de uma divisão temporária do trabalho devem ser mantidos, já é hora de demandar os benefícios da integração do trabalho. A economia política tem até o momento insistido principalmente na divisão. Nós proclamamos a integração, e sustentamos que o ideal de sociedade, isto é, o estado no qual a sociedade já está em marcha, é uma sociedade de trabalho integrado, combinado. Uma sociedade na qual cada indivíduo seja um produtor de ambos, trabalho manual e intelectual; onde cada ser humano que tenha capacitação física seja um trabalhador, e onde cada trabalhador trabalhe tanto no campo quanto na indústria, onde cada agregado de indivíduos, numeroso o suficiente para dispor de certa variedade de recursos naturais, seja uma nação ou uma região, produza e consuma a maior parte de seus próprios produtos agrícolas e industriais.

Mas é claro que, enquanto a sociedade permanecer organizada de tal modo que permita aos proprietários da terra e do capital, sob a proteção do Estado e de direitos históricos, apropriarem-se para si mesmos do excedente anual da produção humana, não será possível efetuar inteiramente tal mudança. Mas o presente sistema industrial, baseado na permanente especialização de funções, carrega já em si mesmo os germes de sua própria ruína. As crises industriais, que a cada dia se tornam mais agudas e prolongadas, e tornam-se ainda piores e mais agudas pelos armamentos e as guerras implicadas no atual sistema, tornam sua manutenção cada vez mais difícil. Além disso, os trabalhadores 
manifestam claramente sua intenção de não mais suportar com paciência as misérias provocadas por cada crise. Cada uma delas acelera o dia em que as atuais instituições da propriedade individual e da produção serão profundamente abaladas com essas lutas internas que irão depender do maior ou menor grau de bom senso das classes hoje privilegiadas.

Também sustentamos, porém, que qualquer tentativa socialista para transformar as atuais relações entre o capital e o trabalho fracassará se não levar em conta as tendências, acima mencionadas, em direção à integração. Essas tendências, na nossa opinião, ainda não receberam a devida atenção por parte das diferentes escolas socialistas - algo que deveria ser feito. Uma sociedade reorganizada terá que abandonar a falácia de pretender especializar as nações, tanto para a produção industrial quanto agrícola. Cada uma deveria contar consigo mesma para a produção de alimentos e de grande parte, se não a maioria, das matériasprimas; deveria buscar os melhores meios de combinar a agricultura e a manufatura, o trabalho no campo e a indústria descentralizada, e deveria proporcionar uma "educação integrada", educação que, sozinha, ensinando tanto ciência quanto artesanato desde a mais tenra infância, pode dotar a sociedade das mulheres e dos homens de que verdadeiramente precisa.

Cada nação como seu próprio agricultor e manufatureiro; cada indivíduo trabalhando no campo e em alguma arte industrial, cada um combinando o conhecimento científico com o prático - tal é, afirmamos, a tendência atual de nações civilizadas.

O prodigioso crescimento de indústrias na GrãBretanha e o desenvolvimento simultâneo do tráfego internacional, que agora permite o transporte de matérias-primas e de artigos alimentícios em uma escala gigantesca, criaram a impressão de que umas poucas nações da Europa Ocidental estavam destinadas a se tornar as manufatureiras do mundo. Elas precisavam apenas, argumentava-se, abastecer o mercado de artigos manufaturados e retirariam de toda a superfície da terra o alimento que elas próprias não pudessem produzir, assim como as matériasprimas necessárias para suas manufaturas. A contínua e crescente rapidez das comunicações transoceânicas e as facilidades crescentes dos fretes, têm contribuindo para fortalecer essa impressão. Se tomamos os quadros sedutores do tráfego internacional, tão admiravelmente elaborados por Neumann Spullart - o estatístico e quase o poeta do comércio mundial - estamos inclinados a cair em êxtase diante dos resultados obtidos. "Porque temos que cultivar o trigo, criar gado e ovelhas, cultivar pomares, passar pelo árduo trabalho do agricultor $\mathrm{e}$ olhar apreensivamente para o céu temendo uma má colheita, quando podemos obter, com muito menos dificuldade, montanhas de grãos da Índia, América, Hungria e Rússia; carne da Nova Zelândia, legumes dos Açores, maçãs do Canadá, uvas de Málaga, e assim por diante?" - exclamam os europeus ocidentais. "Já hoje" dizem - "nosso alimento consiste, mesmo entre os lares mais modestos, de produtos trazidos de todo o mundo. Nossa roupa é feita com fibras cultivadas e lã obtidas em todas as partes do globo. As pradarias da América e Austrália, as montanhas e estepes da Ásia, os desertos gelados das regiões árticas, os desertos da África e as profundezas dos oceanos, os trópicos e as terras do sol da meia-noite, são nossos tributários. Todas as raças de homens contribuem no fornecimento de nossos alimentos básicos e bens de luxo, vestuário cotidiano e trajes de festa, enquanto enviamos em troca o produto de nossa inteligência superior, nosso conhecimento técnico e nossas poderosas capacidades de organização comercial e industrial. Não é uma visão grandiosa essa frenética e complexa troca de produtos através do mundo e que cresceu tão rápido em tão poucos anos?"

Por mais grandiosa que possa ser, não seria um mero pesadelo? Haveria necessidade? A que preço tem sido obtido e quanto tempo irá durar?

\section{(..)}

O progresso deve ser procurado em outro lugar. Ele reside na produção para uso doméstico. Os consumidores dos tecidos de Lancashire ou dos talheres de Sheffield, das sedas de Lyon e da farinha dos moinhos da Hungria não estão na Índia, nem tampouco na África. Os verdadeiros consumidores dos produtos das nossas fábricas devem ser as nossas próprias populações. E eles podem sê-lo, bastando organizar nossa vida econômica de maneira a que possam escapar da sua atual privação. Não há propósito em enviar lojas flutuantes para Nova Guiné com chapéus ingleses ou alemães, quando há muitos potenciais consumidores para os chapéus britânicos em suas próprias ilhas, e para os bens alemães na Alemanha. Em vez de nos preocuparmos com planos para atingir consumidores no exterior, seria melhor tentar responder às seguintes questões: por que o trabalhador britânico, cujas capacidades industriais são tão enaltecidas em discursos políticos; por que o pequeno agricultor escocês ou o camponês irlandês, cujo trabalho obstinado para criar novo solo produtivo a partir de turfeiras é ocasionalmente mencionado, não são consumidores dos tecelões de Lancashire, dos cuteleiros de Sheffield ou dos mineiros de Northumbria ou do País de Gales? Por que os tecelões de Lyon não apenas não 
usam seda, como às vezes não têm comida nos seus sótãos? Por que os camponeses russos vendem seu milho, e por quatro, seis, às vezes oito meses a cada ano são forçados a misturar casca e pastagem do gado a um punhado de farinha para produzir seu pão? Por que as crises de fome são tão comuns em meio aos produtores de trigo e arroz na Índia?

Sob as atuais condições da divisão entre capitalistas e trabalhadores, entre proprietários e as massas vivendo com salários incertos, a difusão da indústria para novas áreas é acompanhada pelos mesmos terríveis fatos da opressão impiedosa, do massacre de crianças, da miséria e da insegurança da vida. 0 relatório dos Inspetores de Fábricas da Rússia, o relatório do Plauen Handelskammer, as investigações italianas e os relatórios sobre as indústrias em crescimento na Índia e no Japão estão repletos das mesmas revelações feitas pelos Relatórios das Comissões Parlamentares entre 1840 e 1842, ou das modernas revelações acerca do "sistema [fabril] precário/explorador" [sweating system] de Whitechapel e Glasgow, da miséria de Londres ou do desemprego de York. O problema do capital e do trabalho é, assim, universalizado; mas, ao mesmo tempo, também se simplifica. 0 retorno a uma situação em que o milho é produzido e os bens são manufaturados para o uso das próprias pessoas que os cultivam e os produzem - este será, sem dúvida, o problema a ser resolvido ao longo dos próximos anos da história europeia. Cada região tornar-se-á sua própria produtora e consumidora dos bens manufaturados. Ao mesmo tempo, isto implica, inevitavelmente, que a região será produtora e consumidora dos produtos agrícolas. (...) 